\title{
KADAR HEMOGLOBIN PADA ORANG DEWASA YANG TINGGAL DI DATARAN TINGGI DENGAN KETINGGIAN YANG BERBEDA
}

\author{
${ }^{1}$ Andreas Waani \\ ${ }^{2}$ J. N. Engka \\ ${ }^{2}$ S. Supit \\ ${ }^{1}$ Kandidat Skripsi Fakultas Kedokteran Universitas Sam Ratulangi Manado \\ ${ }^{2}$ Bagian Fisiologi Fakultas Kedokteran Universitas Sam Ratulangi Manado \\ Email: Andreaswaani@yahoo.com
}

\begin{abstract}
Background: High altitude has an impact on the levels of hemoglobin in an individual. Altitude will cause hypoxia due to the partial pressure of oxygen decreases and body will respond to the process of acclimatization. With the process of acclimatization will occur an increase in levels of haemoglobin to adapt to low oxygen State. This research aims to know the levels of haemoglobin in adults who live in high altitude with different heights. Methods: The subject of the research blood was taken as much as 3cc and processed in a lab using ABX Pentra XL 80 to get an overview of hemoglobin levels. The technique used was Random sampling. This research is a descriptive study. Levels of Hemoglobin is processed using SPSS 17 program. Test of normality indicates significance levels of hemoglobin value of 0.113 . Comparison of the Hemoglobin Levels in tested using mann-whitney test. Result: Results of significance levels of hemoglobin is 0,005, means there are differences in the hemoglobin levels significantly in groups 1 and 2. The average haemoglobin levels for Group 1 is $15.53 \mathrm{~g} / \mathrm{dl}$ and the average haemoglobin levels in the Group 2 was $14.84 \mathrm{~g} / \mathrm{dl}$. Conclusion: There are differences in the levels of hemoglobin on high altitude in the population with different heights.
\end{abstract}

Keywords: Haemolgobin, High Altitude

\begin{abstract}
Abstrak: Latar Belakang: Dataran tinggi memiliki pengaruh terhadap kadar hemoglobin pada suatu individu. Berada di Ketinggian akan menyebabkan hipoksia oleh karena tekanan parsial oksigen yang berkurang dan tubuh akan merespon dengan proses aklimatisasi. Dengan adanya proses aklimatisasi maka akan terjadi peningkatan pada kadar hemoglobin untuk beradaptasi dengan keadaan rendah oksigen. Penelitian ini bertujuan untuk mengetahui kadar hemoglobin pada orang dewasa yang tinggal di dataran tinggi dengan ketinggian yang berbeda. Metode: Subjek penelitian diambil darahnya sebanyak 3cc dan diproses di laboratorium dengan menggunakan alat ABX Pentra XL 80 untuk mendapatkan gambaran kadar hemoglobin. Teknik yang digunakan adalah Random sampling. Penelitian ini bersifat deskriptif dengan rancangan studi potong lintang. Kadar Hemoglobin di proses menggunakan program SPSS 17. Uji normalitas menunjukan nilai signifikansi Kadar hemoglobin sebesar 0.113. Perbandingan Kadar Hemoglobin di uji menggunakan metode mann-whitney test. Hasil: Hasil signifikansi kadar hemoglobin adalah 0.005 , berarti terdapat perbedaan kadar hemoglobin secara signifikan pada kelompok 1 dan 2. Rata-rata kadar hemoglobin untuk kelompok 1 adalah 15.53 g/dl dan Ratarata kadar hemoglobin pada kelompok 2 adalah $14.84 \mathrm{~g} / \mathrm{dl}$. Simpulan: Terdapat perbedaan kadar hemoglobin pada pada penduduk dataran tinggi dengan ketinggian yang berbeda.
\end{abstract}

Kata Kunci: Hemoglobin, Dataran Tinggi.

Indonesia merupakan daerah dataran yang terbagi atas dataran tinggi dan dataran rendah. Dataran tinggi terletak diantara pegunungan atau gunung-gunung dimana pada dataran tinggi pada umumnya merupakan daerah yang padat penduduknya, 
hal ini disebabkan oleh tanahnya yang subur dan udara yang nyaman dan sejuk (1).

Sebagian besar wilayah dataran di propinsi Sulawesi Utara terdiri dari pegunungan dan bukit-bukit diselingi oleh lembah yang membentuk dataran. Gununggunung terletak berantai dengan ketinggian di atas 1000 meter dari permukaan laut. Dataran tinggi secara potensial mempunyai nilai ekonomi bagi daerah (2).

Tantangan terbesar yang dihadapi manusia di ketinggian adalah berkurangnya tekanan parsial oksigen $\left(\mathrm{PO}_{2}\right)$ yang diakibatkan oleh menurunya tekanan barometrik dan tubuh kadang merespon keadaan ini dengan dengan berbagai respon fisiologis contohnya seperti "aklimatisasi" (adaptasi tubuh terhadap iklim/lingkungan baru) sedangkan perubahan fisiologis yang terjadi dari beberapa generasi yang tinggal di dataran tinggi dinamakan "Adaptasi" (3).

Penelitian yang dilakukan oleh Beall C dan Brittenham $G$ dan rekan-rekannya pada penduduk Tibet ketinggian $4000 \mathrm{~m}$ dan Aymara yang ada di Bolivia dengan ketinggian $4065 \mathrm{~m}$ diatas permukaan laut, menunjukan perbedaan hemoglobin dari penduduk kedua daerah tersebut. Penduduk laki-laki dan perempuan di daerah tibet mempunyai kadar hemoglobin 3.5-3.6 gm/dl lebih rendah dari penduduk Aymara di Bolivia (4).

\section{METODE PENELITIAN}

Penelitian ini dilakukan dengan metode analitik deskriptif, metode ini digunakan untuk mengetahui perbandingan antar variabel terikat dan variabel bebas yaitu variabel kadar hemoglobin dan orang dewasa yang tinggal di dataran tinggi yang dilaksanakan pada bulan NovemberDesember 2013. Populasi dalam penelitian ini adalah adalah seluruh penduduk yang tinggal diwilayah kota Tomohon dan Minahasa induk. Jumlaa sampel sebanyak 60 orang laki-laki dewasa. Pengambilan sampel menggunakan metode simple random sampling.

\section{HASIL PENELITIAN}

Tabel 1. Distribusi berdasarkan umur

\begin{tabular}{|c|c|c|c|}
\hline & Umur (Tahun) & Jumlah (n) & Persentase (\%) \\
\hline \multirow[t]{3}{*}{ Paslaten } & $25-40$ & 8 & 27 \\
\hline & $41-60$ & 22 & 73 \\
\hline & Total & 30 & 100 \\
\hline \multirow[t]{4}{*}{ Rurukan } & $25-40$ & 5 & 16 \\
\hline & $41-60$ & 18 & 60 \\
\hline & $61-65$ & 7 & 24 \\
\hline & Total & 30 & 100 \\
\hline
\end{tabular}

Tabel 2. Distribusi kadar hemoglobin

\begin{tabular}{|c|c|c|c|c|c|}
\hline \multicolumn{2}{|c|}{ Rata-rata } & \multirow{2}{*}{$\begin{array}{l}\text { Nilai } \\
\text { (g/dL) }\end{array}$} & \multirow{2}{*}{$\begin{array}{l}\text { Nilai } \\
\text { Tertinggi }\end{array}$} & \multirow{2}{*}{$\begin{array}{l}\text { Simpangan } \\
\text { Terendah }\end{array}$} & \multirow[b]{2}{*}{ Baku } \\
\hline Lokasi & Jumlah & & & & \\
\hline Paslaten & 30 & 15.53 & 18.28 & 8.38 & 2.19636 \\
\hline Rurukan & 30 & 14.84 & 18.10 & 11.39 & 1.42809 \\
\hline
\end{tabular}

Berdasarkan Tabel diatas terdapat jumlah sampel 30 untuk desa paslaten da 30 untuk desa rurukan. Nilai rata-rata kadar hemoglobin penduduk desa paslaten adalah
$15.53 \mathrm{~g} / \mathrm{dL}$ dengan kadar tertinggi 18.28 g/dL, kadar terendah $8.38 \mathrm{~g} / \mathrm{dL}$ dan nilai simpangan baku $2.1 \mathrm{~g} / \mathrm{dL}$. Nilai rata-rata kadar hemoglobin penduduk desa rurukan 
adalah $14.84 \mathrm{~g} / \mathrm{dL}$ dengan kadar tertinggi $18.10 \mathrm{~g} / \mathrm{dL}$, kadar terendah $11.39 \mathrm{~g} / \mathrm{dL}$ dan nilai simpangan baku $1.4 \mathrm{~g} / \mathrm{dL}$.

Dari tabel diatas dapat diketahui jumlah sampel menurut kelompok umur yang paling banyak dari kedua desa yang diteliti adalah umur 41 - 60 tahun di desa paslaten sebanyak 22 jiwa (73\%) dan di desa rurukan sebanyak 18 jiwa (60\%). Di desa rurukan kedua terbanyak adalah umur 61-65 tahun 24\% sebanyak 7 jiwa.

Tabel 3 . Distribusi responden berdasarkan kadar hemoglobin dan umur

\begin{tabular}{lcccc}
\hline & $\begin{array}{c}\text { Umur } \\
(\text { Tahun })\end{array}$ & $\begin{array}{c}\text { Jumlah } \\
(\mathrm{n})\end{array}$ & $\begin{array}{c}\text { Persentase } \\
(\%)\end{array}$ & $\begin{array}{c}\text { Rerata } \\
\text { Kadar Hemoglobin }\end{array}$ \\
\hline \multirow{3}{*}{ Paslaten } & $25-35$ & 4 & 13.3 & $16.11 \mathrm{~g} / \mathrm{dL}$ \\
& $36-46$ & 17 & 57 & $15.8 \mathrm{~g} / \mathrm{dL}$ \\
& $47-57$ & 6 & 20 & $15.2 \mathrm{~g} / \mathrm{dL}$ \\
& $58-60$ & 3 & 10 & $16.6 \mathrm{~g} / \mathrm{dL}$ \\
\hline \multirow{5}{*}{ Rurukan } & & & & \\
& & & & \\
& Umur & Jumlah & Persentase & Rerata \\
& (Tahun) & $(\mathrm{n})$ & $(\%)$ & Kadar Hemoglobin \\
& $25-35$ & 6 & 20 & $16.2 \mathrm{~g} / \mathrm{dL}$ \\
& $36-46$ & 8 & 27 & $14.9 \mathrm{~g} / \mathrm{dL}$ \\
& $47-57$ & 9 & 30 & $14.9 \mathrm{~g} / \mathrm{dL}$ \\
& $58-65$ & 7 & 23 & $13.7 \mathrm{~g} / \mathrm{dL}$ \\
\hline
\end{tabular}

Berdasarkan kedua Tabel diatas dapat dilihat pada tabel pertama bahwa di desa Paslaten responden umur 25-35 tahun berjumlah 4 orang (13.3\%) memiliki ratarata kadar hemoglobin $16.11 \mathrm{~g} / \mathrm{dL}$, responden umur 36-46 tahun yang berjumlah 17 orang (57\%) memiliki rata-rata kadar hemoglobin $15.8 \mathrm{~g} / \mathrm{dL}$, responden umur 4757 tahun yang berjumlah 6 orang (20\%) mempunyai rata-rata kadar hemoglobin $15.22 \mathrm{~g} / \mathrm{dL}$ dan pada responden berumur 5860 tahun yang berjumlah 3 orang (10\%) mempunyai rata-rata kadar hemoglobin 16.6 g/dL.

Pada Tabel kedua dapat dilihat bahwa pada desa Rurukan, responden yang berumur 25-35 tahun berjumlah 6 orang (20\%) memiliki rata-rata kadar hemoglobin $16.2 \mathrm{~g} / \mathrm{dL}$, responden yang berumur 36-46 tahun berjumlah 8 orang (27\%) memiliki rata-rata kadar hemoglobin $14.9 \mathrm{~g} / \mathrm{dL}$, responden yang berumur 47-57 tahun berjumlah 9 (30\%) memiliki rata-rata kadar hemoglobin $14.9 \mathrm{~g} / \mathrm{dL}$ dan responden dengan umur 58-65 berjumlah 7 orang (23\%) memiliki rata-rata kadar hemoglobin $13.7 \mathrm{~g} / \mathrm{dL}$.
Pada penelitian di desa Paslaten, responden yang terbanyak adalah penduduk yang berumur 36- 46 dan pada desa Rurukan, responden yang terbanyak adalah penduduk yang berumur 47-57 tahun.

\section{Hasil uji normalitas Kolmogorov- Smirnov}

Hasil uji normalitas data kadar Hemoglobin pada subjek dengan menggunakan uji kolmogorov-smirnov. Dan dari hasil diatas didapatkan bahwa nilai kadar hemoglobin mempunyai Sig. $0.113>$ 0.05 sehingga ini mengindikasikan bahwa data berdistribusi normal dan bisa dilanjutkan menggunakan uji Mann-Whitney $U$ yang digunakan untuk mendapatkan perbandingan kadar hemoglobin.

\section{Hasil uji Mann-Whitney test}

Dari hasil uji menggunakan MannWhitney test Terlihat bahwa nilai Asymp.Sig./Asymptotic significance nilainya adalah 0.005 . Nilai ini kurang dari 0.05. Maka $\mathrm{H}_{0}$ ditolak atau terdapat perbedaan signifikan pada kadar Hemo- 
globin penduduk yang tinggal di dataran tinggi dengan ketinggian yang berbeda.

\section{BAHASAN}

Pada penelitian yang dilakukan di desa Paslaten dan Rurukan ini, di ikuti oleh 60 sampel warga dengan kelompok usia 34-60 tahun di desa paslaten dan kelompok usia 24-65 tahun di desa rurukan.

Hasil penelitian di desa Paslaten didapatkan 3 sampel (10\%) dengan kadar Hemoglobinnya $<13.2 \mathrm{~g} / \mathrm{dl}$ dan kadar hemoglobin 13.2-17.3 g/dl sebanyak 23 sampel (77\%) dan 17.3-18.28 g/dl sebanyak 4 sampel (13\%).

Hasil penelitian di desa Rurukan didapatkan 3 sampel (10\%) dengan Kadar Hemoglobinnya $<13.2$ g/dl dan kadar hemoglobin 13.2-17.3 g/dl sebanyak 26 sampel (87\%) dengan 1 sampel (3\%) dengan kadar Hemoglobin 18.10 g/dl.

Dari kedua hasil penelitian diatas didapatkan bahwa desa Paslaten mempunyai rata-rata kadar hemoglobin lebih tinggi dibandingkan dengan desa Rurukan. Hasil yang didapatkan berbanding terbalik dengan hasil-hasil penelitian sebelumnya yang dilakukan oleh Beall C.M dkk yang dilakukan pada penduduk Aymara Bolivia dan Tibet dimana didapatkan kadar hemoglobin pada penduduk Aymara mempunyai rata-rata lebih tinggi dibanding dengan penduduk tibet yang mempunyai elevasi lebih rendah (4).

Penyebab dari rendahnya kadar hemoglobin pada penduduk rurukan bisa disebabkan oleh beberapa hal, yaitu asupan nutrisi sehari-hari penduduk, anemia oleh karena inflamasi, penyakit kronik dan kemungkinan pengaruh pestisida dikarenakan rata-rata penduduk yang diteliti dulunya pernah menjadi petani.

\section{Asupan nutrisi sehari-hari dan pestisida}

Seperti yang diketahui, asupan zat besi sangat dibutuhkan untuk pembentukan hemoglobin, dan kurangnya asupan zat besi bisa mempengaruhi kadar hemoglobin pada suatu individu (5). Asupan asam folat dan vitamin B 12 juga dapat meningkatkan produksi hemoglobin seperti yang diteliti oleh Muwakhidah terhadap pekerja wanita di sukoharjo, didapatkan peningkatan kadar hemoglobin setelah pemberian vitamin B 12, oleh karena Vitamin B 12 dapat membantu proses metabolisme besi dalam tubuh (6). Pestisida dikatakan dapat mempengaruhi kadar hemoglobin oleh karena racun yang terkandung didalam pestisida tersebut tetapi penelitian yang dilakukan oleh Runia Y.A terhadap petanipetani di desa Tejosari Kecamatan Ngablak Magelang dan dari jumlah 75 petani didapatkan 63 petani menderita anemia tetapi tidak didapatkan hubungan antara penggunaan pestisida terhadap anemia yang diderita , melainkan anemia yang diderita petani merupakan akibat asupan nutrisi dari petani-petani yang tidak adekuat (7).

\section{Anemia oleh karena inflamasi dan penyakit kronik}

Anemia oleh karena inflamasi dan penyakit kronis yang disebabkan oleh karena sel-sel darah merah yang tidak berfungsi secara normal, sehingga sel-sel darah tersebut tidak dapat menyerap dan menggunakan besi secara efisien. Selain itu, tubuh juga tidak dapat merespon eritropoietin secara normal. Eritropoietin adalah hormon yang dibuat oleh ginjal yang fungsinya adalah merangsang sumsum tulang untuk menghasilkan sel darah merah. Seiring waktu, hal ini dapat menyebabkan penurunan sel darah merah dalam tubuh. Beberapa penyakit kronis yang mengarah ke anemia oleh karena inflamasi dan penyakit kronik adalah penyakit menular seperti TBC, HIV/AIDS, penyakit ginjal, dan kanker. Anemia yang disebabkan oleh inflamasi adalah mekanisme yang alami dan berfungsi untuk melindungi tubuh. Ketika tubuh mendapat ancaman dari mikroorganisme yang menginfeksi tubuh, besi akan dikirim ke ferritin dan akan disimpan agar mikroorganisme tidak dapat mendapat besi tersebut dan besi yang tersedia, hanya dalam jumlah cukup untuk digunakan dalam pembentukan sel darah merah. Seiring waktu penderita akan 
mengalami penurunan ringan dari kadar hemoglobin (8).

Beberapa teori diatas kemungkinan bisa menyebabkan kadar hemoglobin yang rendah pada penduduk di desa Rurukan yang seharusnya lebih tinggi dari penduduk Paslaten yang elevasi datarannya lebih rendah. Penelitian di desa paslaten dan desa rurukan ini masih memiliki kelemahan seperti kurangnya kesadaran penduduk untuk melakukan pemeriksaan, halangan cuaca dan ada beberapa warga yang menolak mengikuti penelitian dikarenakan takut jarum suntik.

\section{SIMPULAN}

Pada penelitian yang dilakukan pada 60 sampel pria di desa Paslaten dan desa Rurukan didapatkan adanya perbedaan kadar hemoglobin yang signifikan pada penduduk yang tinggal di dataran tinggi dengan ketinggian berbeda. Nilai Rata-rata kadar hemoglobin $15.53 \mathrm{~g} / \mathrm{dl}$ di desa paslaten dan nilai rata-rata kadar hemoglobin $14.84 \mathrm{~g} / \mathrm{dl}$ di desa rurukan menunjukan bahwa desa paslaten memiliki rata-rata Kadar hemoglobin lebih tinggi dari desa rurukan yang mempunyai dataran lebih tinggi.

\section{DAFTAR PUSTAKA}

1. Geografi Regional Indonesia. Letak Indonesia. Diunduh di http://file. upi.edu/.../GRI_Gabungan_Cetak.pdf
2. Geografi Sulawesi Utara. Gunung,dataran rendah dan dataran tinggi di Sulawesi Utara Tersedia di: http://www.seputarsulut. com/geografi-sulawesi-utara/

3. Height and Hematology. The story of haemoglobin on high altitude. Tersedia di: http://www.ncbi.nlm.nih.gov/ pmc/articles/PMC2599997/

4. Beall CM, Brittenham GM. Hemoglobin concentration of high-altitude tibetans and bolivian aymara diunduh dari: www. case.edu/affil/tibet/.../Hemoglobin\%20Conc -Tibetans.pdf

5. Mulyatno K.C. Pembentukan Hemoglobin. Diunduh dari: http://www.itd.unair.ac.id/ files/pdf/protocol1/PEMBENTUKAN\%20H EMOGLOBIN.pdf

6. Muwakhidah. Efek Suplementasi Fe, Asam Folat dan Vitamin B 12 Terhadap Terhadap Peningkatan Kadar Hemoglobin Pada Pekerja Wanita di Kabupaten Sukoharjo Diunduh dari: http://eprints.undip.ac.id/ 18331/1/Muwakhidah.pdf

7. Runia Y.A. Faktor-faktor yang Berhubungan dengan Keracunan Pestisida Organofosfat, Kerbamat dan Kejadian Anemia pada Petani Hortikultura di Desa Tejosari Kecamatan Ngablak Kabupaten Magelang. Diunduh dari: http://eprints. undip.ac.id/17532/YODENCA_ASTI_RUN IA.pdf

8. National Institute of Diabetes and Digestive and Kidney disease. Anemia of Inflmmation and Chronic Disease. Diunduh di: http://hematologic.niddk.nih.gov/ PDF/Anemia-ChronicDisease_508.pdf 